\title{
Chromium Chains as Polydentate Fluoride Ligands for Actinides and Group IV Metals
}

DOI:

10.1039/C8DT00803E

Document Version

Accepted author manuscript

Link to publication record in Manchester Research Explorer

\section{Citation for published version (APA):}

Leng, J-D., Kostopoulos, A., Isherwood, L., Ariciu, A-M., Tuna, F., Vitorica-Yrezabal, I., Pritchard, R., Whitehead, G., Timco, G., Mills, D., \& Winpenny, R. (2018). Chromium Chains as Polydentate Fluoride Ligands for Actinides and Group IV Metals. Dalton Transactions, 47(18), 6361-6369. https://doi.org/10.1039/C8DT00803E

\section{Published in:}

Dalton Transactions

\section{Citing this paper}

Please note that where the full-text provided on Manchester Research Explorer is the Author Accepted Manuscript or Proof version this may differ from the final Published version. If citing, it is advised that you check and use the publisher's definitive version.

\section{General rights}

Copyright and moral rights for the publications made accessible in the Research Explorer are retained by the authors and/or other copyright owners and it is a condition of accessing publications that users recognise and abide by the legal requirements associated with these rights.

\section{Takedown policy}

If you believe that this document breaches copyright please refer to the University of Manchester's Takedown Procedures [http://man.ac.uk/04Y6Bo] or contact uml.scholarlycommunications@manchester.ac.uk providing relevant details, so we can investigate your claim.

\section{OPEN ACCESS}




\section{Journal Name}

\section{ARTICLE}

\section{Chromium Chains as Polydentate Fluoride Ligands for Actinides and Group IV Metals}

Received 00th January 20xx, Accepted 00th January 20xx

DOI: $10.1039 / \times 0 \times x 00000 x$
Ji-Dong Leng, ${ }^{a, b}$ Andreas K. Kostopoulos, ${ }^{b}$ Liam H. Isherwood, ${ }^{b}$ Ana-Maria Ariciu, , , Floriana Tuna, Iñigo J. Vitórica-Yrezábal, ${ }^{b}$ Robin G. Pritchard, ${ }^{b}$ George F. S. Whitehead, ${ }^{b}$ Grigore A. Timco, ${ }^{b}$ David P. Mills, ${ }^{b}$ and Richard E. P. Winpenny*

The reactions of $\left\{\mathrm{Cr}_{6}\right\}$ horseshoe chains $\left\{\left[{ }^{\mathrm{n}} \mathrm{Pr}_{2} \mathrm{NH}_{2}\right]_{3}\left[\mathrm{Cr}_{6} \mathrm{~F}_{11}\left(\mathrm{O}_{2} \mathrm{C}^{\mathrm{t}} \mathrm{Bu}\right)_{10}\right]\right\}_{2}, 1$ and precursors of actinides and group IV metals led to a series of ring complexes [ $\left.{ }^{\mathrm{n}} \mathrm{Pr}_{2} \mathrm{NH}_{2}\right]\left[\mathrm{Cr}_{7} \mathrm{TiF}_{6} \mathrm{O}_{2}\left(\mathrm{O}_{2} \mathrm{C}^{\mathrm{t}} \mathrm{Bu}\right)_{16}\right], \mathbf{2},\left[{ }^{\mathrm{n}} \mathrm{Pr}_{2} \mathrm{NH}_{2}\right]\left[\mathrm{Cr}_{6} \mathrm{Ti}_{2} \mathrm{~F}_{5} \mathrm{O}_{3}\left(\mathrm{O}_{2} \mathrm{C}^{\mathrm{t}} \mathrm{Bu}\right)_{16}\right], \mathbf{3},\left[\mathrm{Cr}_{6} \mathrm{ThF}_{7}\left(\mathrm{O}_{2} \mathrm{C}^{t} \mathrm{Bu}_{15}\left(\mathrm{Me}_{2} \mathrm{SO}\right)\right]\right.$, 4, $\left[\left({ }^{n} \mathrm{Pr}_{2} \mathrm{NH}_{2}\right)_{2}\left(\mathrm{Cr}_{6} \mathrm{Th}_{2} \mathrm{~F}_{12}\left(\mathrm{O}_{2} \mathrm{C}^{t} \mathrm{Bu}\right)_{16}\right)\right], 5$ and $\left[{ }^{n} \mathrm{Pr}_{2} \mathrm{NH}_{2}\right]\left[\mathrm{Cr}_{6} \mathrm{U}_{2} \mathrm{O}_{2} \mathrm{~F}_{8}\left(\mathrm{O}_{2} \mathrm{C}^{t} \mathrm{Bu}\right)_{16}\left(\mathrm{Me}_{2} \mathrm{SO}\right)\right], 6$. X-ray structure studies indicate that the $\left\{\mathrm{Cr}_{6}\right\}$ chains maintain their structures in these complexes, acting as polydentate fluoride ligands. Their static magnetic properties were measured and fitted by isotropic exchange Hamiltonian. In accordance with $\mathbf{1}$, the magnetic exchanges between $\mathrm{Cr}^{\prime \prime \prime}$ are antiferromagnetic, while the exchange interactions can be modified by the tetravalent metals. For compound 6, ferromagnetic exchanges $J_{C r-U}$ and $J_{U-U}$ are obtained. EPR spectra of compounds 2-5 were measured at Q band and were simulated. The spectrum of $\mathbf{2}$ has the same profile as $\left\{\mathrm{Cr}_{7} \mathrm{Cd}\right\}$ and $\left\{\mathrm{Cr}_{7} \mathrm{Zn}\right\}$ rings with a ground state $S=3 / 2 . \mathbf{3}, \mathbf{4}$ and 5 give similar EPR spectra with $S=0$ ground states.

\section{Introduction}

We have been focusing on anti-ferromagnetically coupled heterometallic rings because of their interesting magnetic frustration behaviour and potential application in quantum information processing. ${ }^{1} A$ series of $\left\{\mathrm{Cr}_{7} \mathrm{M}\right\}$ rings and supramolecular architectures derived from them have been synthesized and investigated. ${ }^{2}$ The $\left\{\mathrm{Cr}_{7} \mathrm{M}\right\}$ rings are obtained by one-pot reaction of $\mathrm{CrF}_{3} \cdot 4 \mathrm{H}_{2} \mathrm{O}$ an appropriate carboxylic acid, a secondary amine and corresponding metal (II) salts.

An alternative route uses anionic $\left\{\mathrm{Cr}_{6}\right\}$ chains as ligands to bind metal ions. The $\left\{\mathrm{Cr}_{6}\right\}$ chains $\left\{\left[{ }^{\mathrm{n}} \mathrm{Pr}_{2} \mathrm{NH}_{2}\right]_{3}\left[\mathrm{Cr}_{6} \mathrm{~F}_{11}\left(\mathrm{O}_{2} \mathrm{C}^{\mathrm{t} B u}\right)_{10}\right]\right\}_{2}$, 1, and $\left[\left(\mathrm{Et}_{2} \mathrm{NH}_{2}\right)_{3}\left\{\mathrm{Cr}_{6} \mathrm{~F}_{11}\left(\mathrm{O}_{2} \mathrm{C}{ }^{\mathrm{t}} \mathrm{Bu}\right)_{10}\right\}\right]_{2}$ adopt a " horseshoe" motif of chromium centres, each with six terminal fluoride ligands. Reactions between $\left\{\mathrm{Cr}_{6}\right\}$ chains and precursors of sodium ${ }^{3}$ and lanthanides ${ }^{4}$ lead to a series of $\left\{\left(\mathrm{Cr}_{6}\right) \mathrm{M}_{\mathrm{x}}\right\}_{n}(\mathrm{M}=\mathrm{Na}, \mathrm{Y}, \mathrm{Ce}, \mathrm{Gd})$ clusters including cage, ring and bicycle motifs. In the obtained clusters, the $\left\{\mathrm{Cr}_{6}\right\}$ horseshoe chains maintain their characteristic structures and bind the metal ions with the terminal fluoride ions. These results have shown that $\left\{\mathrm{Cr}_{6}\right\}$ chains can act as fairly robust polydentate fluoride ligands for hard metals.

Fluoride is widely used to extract actinides because the resultant compounds are insoluble in water and can be

\footnotetext{
a. Guangzhou Key Laboratory for Environmentally Functional Materials and Technology, School of Chemistry and Chemical Engineering, Guangzhou University, 230 Wai Huan Xi Road, Guangzhou Higher Education Mega Center, Guangzhou, 510006, P. R. China.

${ }^{b}$ School of Chemistry and Photon Science Institute, University of Manchester, Oxford Road, Manchester, M13 9PL, UK. E-mail:

richard.winpenny@manchester.ac.uk

Electronic Supplementary Information (ESI) available: [details of any supplementary information available should be included here]. See DOI: 10.1039/x0xx00000x
}

separated with redox reactions. ${ }^{5}$ The monovalency and high electronegativity of fluorides lead to a very limited number of polydentate fluoride donor ligands (i.e. $\mathrm{SiF}_{6}{ }^{2-}$ can as a bridging ligand, but this is quite rare $^{6}$ ). As these chains bind electropositive elements, we reasoned they would bind strongly to the actinides and prevent the precipitation of extremely insoluble $\mathrm{AnF}_{4}$ salts. The development of new ligands for actinide binding is a very important field of chemistry, especially in the context of nuclear fuel processing and recycling.

In addition, the clusters combining paramagnetic transitionmetal and actinide ions may exhibit interesting single-molecule magnets (SMMs) behaviours. For example, M. Mazzanti et.al have reported a ring-shaped $\left\{\left[\mathrm{UO}_{2}(\text { salen })\right]_{2} \mathrm{Mn}(\mathrm{Py})_{3}\right\}_{6}$ as an SMM with a $U_{\text {eff }}=99 \mathrm{~cm}^{-1}$.

The aim of this work was to investigate whether we could make $\left\{\mathrm{Cr}_{6}\right\}$ chains bind to tetravalent actinides $\mathrm{Th}^{\mathrm{IV}}$ and $\mathrm{U}^{\mathrm{IV}}$. Prior to experiments involving radioactive materials, we studied the binding of $\left\{\mathrm{Cr}_{6}\right\}$ chains to titanium(IV). The reactions of 1 with $\mathrm{Ti}^{\mathrm{iV}}$ precursors led to the isolation of two eight membered rings $\left[{ }^{\mathrm{n}} \mathrm{Pr}_{2} \mathrm{NH}_{2}\right]\left[\mathrm{Cr}_{7} \mathrm{TiF}_{6} \mathrm{O}_{2}\left(\mathrm{O}_{2} \mathrm{C}^{\mathrm{t}} \mathrm{Bu}\right)_{16}\right] \quad \mathbf{2}$ and $\left[{ }^{\mathrm{n}} \mathrm{Pr}_{2} \mathrm{NH}_{2}\right]$ $\left[\mathrm{Cr}_{6} \mathrm{Ti}_{2} \mathrm{~F}_{5} \mathrm{O}_{3}\left(\mathrm{O}_{2} \mathrm{C}^{\mathrm{t}} \mathrm{Bu}\right)_{16}\right]$ 3. Similar reactions of $\mathbf{1}$ with $\mathrm{Th}^{\mathrm{IV}}$ and $\mathrm{U}^{\mathrm{IV}}$ precursors led to ring structures $\left[\mathrm{Cr}_{6} \operatorname{ThF}_{7}\left(\mathrm{O}_{2} \mathrm{C}^{\mathrm{t}} \mathrm{Bu}\right)_{15}\left(\mathrm{Me}_{2} \mathrm{SO}\right)\right] \mathbf{4}$, $\left[\left({ }^{\mathrm{n}} \mathrm{Pr}_{2} \mathrm{NH}_{2}\right)_{2}\left(\mathrm{Cr}_{6} \mathrm{Th}_{2} \mathrm{~F}_{12}\left(\mathrm{O}_{2} \mathrm{C}^{\mathrm{t}} \mathrm{Bu}\right)_{16}\right)\right] \quad \mathbf{5}$ and $\left[{ }^{n} \mathrm{Pr}_{2} \mathrm{NH}_{2}\right]\left[\mathrm{Cr}_{6} \mathrm{U}_{2} \mathrm{O}_{2} \mathrm{~F}_{8}\left(\mathrm{O}_{2} \mathrm{C}^{t} \mathrm{Bu}\right)_{16}\left(\mathrm{Me}_{2} \mathrm{SO}\right)\right]$ 6. Herein we report their syntheses, structures and magnetic properties.

\section{Experimental section}

General information 
Unless stated otherwise, all reagents and solvents were purchased from commercial sources and used without further purification.

For $U^{\mathrm{IV}}$ reactions, all manipulations were carried out using standard Schlenk and glove box techniques under an atmosphere of dry argon. Solvents were dried by refluxing over potassium and degassed before use. All solvents were stored over potassium mirrors. Most solid reagents were dried under vacuum for four hours and most liquid reagents were dried over $4 \AA$ A molecular sieves and distilled before use.

Analytical data were obtained by the microanalysis laboratory at the University of Manchester-carbon, hydrogen, nitrogen analysis (CHN) by a Flash 2000 elemental analyser and metals analysis by Thermo iCap 6300 inductively coupled plasma optical emission spectroscopy (ICP-OES).

Thermo Fisher Scientific "Exactive Plus EMR Orbitrap" mass spectrometer was used for mass spectrometry analysis. The samples were ionised in the electrospray ion source operated in both positive and negative modes, $\sim 3.5 \mathrm{kV}$ was applied to the capillary. The ions were detected using electrostatic trap with mass resolution of $\sim 140000$ and stability sufficient to achieve a precision of $<5 \mathrm{ppm}$ for mass measurements.

\section{Starting materials}

The starting materials $\left\{\left[{ }^{\mathrm{n}} \mathrm{Pr}_{2} \mathrm{NH}_{2}\right]_{3}\left[\mathrm{Cr}_{6} \mathrm{~F}_{11}\left(\mathrm{O}_{2} \mathrm{C}^{\mathrm{t}} \mathrm{Bu}\right)_{10}\right]\right\}_{2}, \mathbf{1}$, and $\left[\left(\mathrm{Et}_{2} \mathrm{NH}_{2}\right)_{3}\left\{\mathrm{Cr}_{6} \mathrm{~F}_{11}\left(\mathrm{O}_{2} \mathrm{C}^{\mathrm{t}} \mathrm{Bu}\right)_{10}\right\}\right]_{2}$ were prepared according to literature procedures. ${ }^{3}$ The preparation of $\mathrm{Ti}_{8} \mathrm{O}_{8}\left(\mathrm{O}_{2} \mathrm{C}^{\mathrm{t}} \mathrm{Bu}\right)_{16}$. $(\mathrm{MeCN})_{2}$ was adapted from literature. ${ }^{8}$

\section{Synthesis of compounds}

\section{[ $\left.{ }^{\mathrm{n}} \mathrm{Pr}_{2} \mathrm{NH}_{2}\right]\left[\mathrm{Cr}_{7} \mathrm{TiF}_{6} \mathrm{O}_{2}\left(\mathrm{O}_{2} \mathrm{C}^{\mathrm{t}} \mathrm{Bu}\right)_{16}\right], 2$}

$\left\{\left[{ }^{\mathrm{n}} \mathrm{Pr}_{2} \mathrm{NH}_{2}\right]_{3}\left[\mathrm{Cr}_{6} \mathrm{~F}_{11}\left(\mathrm{O}_{2} \mathrm{C}^{\mathrm{t}} \mathrm{Bu}\right)_{10}\right]\right\}_{2}, \quad(3.0 \mathrm{~g}, 0.80 \mathrm{mmol})$, titanyl acetylacetonate $(0.833 \mathrm{~g}, 3.18 \mathrm{mmol})$ and pivalic acid $(14.0 \mathrm{~g}$, $137 \mathrm{mmol}$ ) were placed in a $150 \mathrm{~mL}$ Teflon Erlenmeyer flask. The flask was placed in a silicone oil bath at $140{ }^{\circ} \mathrm{C}$ for $20 \mathrm{hrs}$ and stirred continuously. After heating, the reaction mixture had dried to a green powder due to the evaporation of excess pivalic acid. Upon cooling to ambient temperature, acetone:MeCN $(1: 1,50 \mathrm{~mL})$ was added to the flask and stirred for $4 \mathrm{hr}$. A green solid was obtained via vacuum filtration, washed with $\mathrm{Et}_{2} \mathrm{O}: \mathrm{MeCN}(1: 1,25 \mathrm{~mL})$ and dried in air. TLC shows movement of the least polar species, 2, from baseline using toluene, further isolable species show movement using EtOAc and $\mathrm{Et}_{2} \mathrm{O}$. Separation of $\mathbf{2}$ on silica column (length $=25 \mathrm{~cm}$ ) is achieved using toluene as the eluent. Rotary evaporation of the toluene fraction under reduced pressure yields $\mathbf{2}$ as a green powder. Single crystals were grown after dissolution in a $\mathrm{Et}_{2} \mathrm{O}: \mathrm{MeCN}$ mixture (7:3).

Yield: $1.95 \mathrm{~g}$ (62.4\% based on $\mathrm{Cr}$ ). Elemental analysis calculated (\%) for $\mathrm{C}_{86} \mathrm{H}_{160} \mathrm{O}_{34} \mathrm{~N}_{1} \mathrm{Cr}_{7} \mathrm{Ti}_{1} \mathrm{~F}_{6}$ : $\mathrm{Cr}$ 15.97, Ti 2.10, C 45.34, H 7.08, N 0.61; Found (\%) Cr 15.15, Ti 2.30, C 46.54, H 7.52, N 0.36. ES-MS $(T H F, m / z):+2278[\mathrm{M}+\mathrm{H}]^{+} ;+2300[\mathrm{M}+\mathrm{Na}]^{+}$.

\section{$\mathrm{Ti}_{8} \mathrm{O}_{8}\left(\mathrm{O}_{2} \mathrm{C}^{\mathrm{t}} \mathrm{Bu}\right)_{16} \cdot(\mathrm{MeCN})_{2}$}

Pivalic acid was distilled prior to use by hydrolysis of trimethyl acetic anhydride. Standard distillation apparatus was used to reflux trimethyl acetic anhydride at $165^{\circ} \mathrm{C}$. Anhydrous pivalic acid $(17.5 \mathrm{~g}, 170 \mathrm{mmol})$ dissolved in dry MeCN $(40 \mathrm{~g}, 970 \mathrm{mmol})$ was added to a 2-necked round bottomed flask, flushed with $\mathrm{N}_{2}$. Titanium (IV) isopropoxide (5 g, $17 \mathrm{mmol})$ and dry MeCN (8 g, $195 \mathrm{mmol}$ ) were added dropwise to the flask, through a suba seal, using a syringe. After stirring at room temperature for a few minutes, all reactants were visibly solvated. Following this, the reaction mixture was refluxed at $100{ }^{\circ} \mathrm{C}$ for $4 \mathrm{hr}$. White translucent crystals formed at the base of the flask. The remaining $\mathrm{MeCN}$ was evaporated under reduced pressure and the white crystals of $\mathrm{Ti}_{8} \mathrm{O}_{8}\left(\mathrm{O}_{2} \mathrm{C}^{t} \mathrm{Bu}\right)_{16}$. $(\mathrm{MeCN})_{2}$ were used in further synthetic transformations without further purification. Yield: $4.19 \mathrm{~g}$ (89.2 \% based on $\mathrm{Ti}$ ) Elemental analysis calculated (\%) for $\mathrm{C}_{84} \mathrm{H}_{150} \mathrm{O}_{40} \mathrm{Ti}_{8} \mathrm{~N}_{2}$ : C 45.63, H 6.84, N 1.27, $\mathrm{Ti}$ 17.32; Found (\%) C 46.25, H 6.91, N 0.77, Ti 16.75.

ES-MS $(\mathrm{MeOH}, \mathrm{m} / \mathrm{z})+2026\left[\mathrm{M}-(\mathrm{MeCN})_{2}-\mathrm{O}_{2} \mathrm{C}^{\mathrm{t}} \mathrm{Bu}\right]^{+} ;+2153[\mathrm{M}-$ $\left.(\mathrm{MeCN})_{2}+\mathrm{Na}\right]^{+}$.

\section{Synthesis of $\left[{ }^{\mathrm{n}} \mathrm{Pr}_{2} \mathrm{NH}_{2}\right]\left[\mathrm{Cr}_{6} \mathrm{~F}_{5} \mathrm{Ti}_{2} \mathrm{O}_{3}\left(\mathrm{O}_{2} \mathrm{C}^{\mathrm{t}} \mathrm{Bu}\right)_{16}\right], 3$}

$\left\{\left[{ }^{\mathrm{n}} \mathrm{Pr}_{2} \mathrm{NH}_{2}\right]_{3}\left[\mathrm{Cr}_{6} \mathrm{~F}_{11}\left(\mathrm{O}_{2} \mathrm{C}^{\mathrm{t}} \mathrm{Bu}\right)_{10}\right]\right\}_{2}, \quad(3.0 \mathrm{~g}, \quad 0.80 \quad \mathrm{mmol})$, $\mathrm{Ti}_{8} \mathrm{O}_{8}\left(\mathrm{O}_{2} \mathrm{C}^{\mathrm{t}} \mathrm{Bu}\right)_{16} .(\mathrm{MeCN})_{2},(1.70 \mathrm{~g}, 0.8 \mathrm{mmol})$ and pivalic acid (14.0g, $137 \mathrm{mmol}$ ) were added to a $150 \mathrm{~mL}$ Teflon Erlenmeyer flask. The flask was placed in a silicone oil bath at $140{ }^{\circ} \mathrm{C}$ for 3 hrs and stirred continuously. After cooling to room temperature, acetone:MeCN $(1: 1,50 \mathrm{~mL})$ was added with continued stirring for $5 \mathrm{hr}$. A green microcrystalline solid was obtained via vacuum filtration. The product, 3, was extracted using $\mathrm{Et}_{2} \mathrm{O}(30 \mathrm{~mL})$ and precipitated out of solution after addition of $\mathrm{MeCN}(30 \mathrm{~mL})$. Finally, the product is filtered and washed with $\mathrm{Et}_{2} \mathrm{O}$ and acetonitrile $(1: 1,25 \mathrm{~mL})$. TLC shows movement of least polar species, 3, from baseline using toluene, a further compound shows movement in $\mathrm{Et}_{2} \mathrm{O}$. Separation of $\mathbf{3}$ on silica column (length $=25 \mathrm{~cm}$ ) was achieved using toluene:EtOAc (3:1) as the eluent. The solvent mixture was then evaporated under reduced pressure. $\mathrm{Et}_{2} \mathrm{O}$ was used to produce single crystals of $\mathbf{3}$ for XRD measurements.

Yield: $2.89 \mathrm{~g}, 79.5 \%$ based on Cr. Elemental analysis calculated (\%) for $\mathrm{C}_{86} \mathrm{H}_{160} \mathrm{O}_{35} \mathrm{~N}_{1} \mathrm{Cr}_{6} \mathrm{Ti}_{2} \mathrm{~F}_{5}$ : $\mathrm{Cr}$ 13.74, Ti 4.21, C 45.48, $\mathrm{H}$ 7.10, N 0.62; Found $\mathrm{Cr} 14.11$, Ti 4.05, C 45.98, H 7.26, N 0.66 . ES-MS (THF, m/z): +2169 [M - $\left.{ }_{2} \mathrm{C}^{\mathrm{t}} \mathrm{Bu}\right]^{+},+2271[\mathrm{M}+\mathrm{H}]^{+} ;+2293$ $[\mathrm{M}+\mathrm{Na}]^{+} ;+2311[\mathrm{M}+\mathrm{K}]^{+}$.

\section{$\left[\mathrm{Th}\left(\mathrm{O}_{2} \mathrm{C}^{\mathrm{t}} \mathrm{Bu}\right)_{4}\right]_{\mathrm{n}}$}

$\mathrm{Th}\left(\mathrm{NO}_{3}\right)_{4}\left(\mathrm{H}_{2} \mathrm{O}\right)_{4}(2.49 \mathrm{~g}, 4.51 \mathrm{mmol})$ was refluxed in $\mathrm{HO}_{2} \mathrm{C}^{\mathrm{t}} \mathrm{Bu}$ (100 g) with stirring for $12 \mathrm{~h}$ at $120^{\circ} \mathrm{C}$ with slow $\mathrm{N}_{2}$ flow to remove the $\mathrm{NO}_{2}$. Then the reaction mixture was allowed to cool to room temperature. The product was then collected by filtration and washed with further $\mathrm{Et}_{2} \mathrm{O}$ and dried in air. Yield: $0.58 \mathrm{~g}, 20 \%$ based on Th. Elemental analysis calculated (\%) for $\mathrm{ThC}_{20} \mathrm{H}_{36} \mathrm{O}_{8}$ : C 37.74, H 5.70; found (\%) C 37.72, H 5.66.

\section{$\left[\mathrm{U}_{4} \mathrm{O}_{2}\left(\mathrm{O}_{2} \mathrm{C}^{\mathrm{t}} \mathrm{Bu}\right)_{12}\right]$ (Toluene) $)_{1.5}$}

$\mathrm{UCl}_{4}(0.38 \mathrm{~g}, 1 \mathrm{mmol})$ and $\mathrm{KO}_{2} \mathrm{C}^{\mathrm{t}} \mathrm{Bu}(0.56 \mathrm{~g}, 4 \mathrm{mmol})$ were refluxed with stirring in toluene for $12 \mathrm{~h}$ at $120^{\circ} \mathrm{C}$. Then the reaction mixture was allowed to cool to room temperature. The solution was filtered and the filtrate was concentrated and stored at $5{ }^{\circ} \mathrm{C}$ to give the crystalline product as green needles. Crystalline product yield: $0.224 \mathrm{~g}, 38 \%$ based on $\mathrm{U}$. 
$\left[\mathrm{Cr}_{6} \mathrm{ThF}_{7}\left(\mathrm{O}_{2} \mathrm{C}^{t} \mathrm{Bu}\right)_{15}\left(\mathrm{Me}_{2} \mathrm{SO}\right)\right]\left(\mathrm{HO}_{2} \mathrm{C}^{t} \mathrm{Bu}\right)(\mathrm{MeCN})(\mathrm{THF})_{0.5}, 4$

$\left[\mathrm{Th}\left(\mathrm{O}_{2} \mathrm{C}^{\mathrm{t}} \mathrm{Bu}\right)_{4}\right]_{\mathrm{n}}(0.127 \mathrm{~g}, 0.2 \mathrm{mmol})$, pivalic acid $(1 \mathrm{~g}, 9.8 \mathrm{mmol})$, DMSO $(0.8 \mathrm{~g})$ and $\left\{\left[{ }^{\mathrm{n}} \mathrm{Pr}_{2} \mathrm{NH}_{2}\right]_{3}\left[\mathrm{Cr}_{6} \mathrm{~F}_{11}\left(\mathrm{O}_{2} \mathrm{C}^{\mathrm{t}} \mathrm{Bu}\right)_{10}\right]\right\}_{2}(0.53 \mathrm{~g}, 0.15$ $\mathrm{mmol}$ ) were stirred at room temperature with THF (35 $\mathrm{ml})$ for $15 \mathrm{~min}$, then MeCN (20 ml) added and stirring continued for 18 hours at room temperature. The solution was then filtered and the filtrate was left undisturbed for slow evaporation in a partially open flask. After 1 week a small amount of crystalline product including crystals suitable for X-ray structure studies were collected by filtration and washed with MeCN.

Yield: $0.096 \mathrm{~g}, 19.5 \%$ based on Th. Elemental analysis calculated (\%) for $\mathrm{ThCr}_{6} \mathrm{~F}_{7} \mathrm{C}_{86} \mathrm{H}_{158} \mathrm{O}_{33.5} \mathrm{NS}$ : Th 9.61, $\mathrm{Cr} 12.93, \mathrm{C} 41.80, \mathrm{H} 6.43$ N 0.58; found (\%) Th 9.70, Cr 12.44, C 40.40, H 6.4, N 0.64 .

\section{$\left[\left({ }^{n} \mathrm{Pr}_{2} \mathrm{NH}_{2}\right)_{2}\left(\mathrm{Cr}_{6} \mathrm{Th}_{2} \mathrm{~F}_{12}\left(\mathrm{O}_{2} \mathrm{C}^{t} \mathrm{Bu}\right)_{16}\right)\right]\left({ }^{n} \mathrm{Pr}_{2} \mathrm{NH}\right)_{2}\left(\mathrm{Et}_{2} \mathrm{O}\right), 5$}

$\left[\mathrm{Th}\left(\mathrm{O}_{2} \mathrm{C}^{\mathrm{t}} \mathrm{Bu}\right)_{4}\right]_{\mathrm{n}}(0.255 \mathrm{~g}, 0.4 \mathrm{mmol})$, pivalic acid $(1 \mathrm{~g}, 9.8 \mathrm{mmol})$, DMSO $(0.8 \mathrm{~g})$ and $\left[\left({ }^{n} \mathrm{Pr}_{2} \mathrm{NH}_{2}\right)_{3}\left\{\mathrm{Cr}_{6} \mathrm{~F}_{11}\left(\mathrm{O}_{2} \mathrm{CtBu}\right)_{10}\right\}\right]_{2}(0.35 \mathrm{~g}, 0.1$ $\mathrm{mmol})$ were dissolved in toluene $(80 \mathrm{~mL})$ and refluxed with stirring for $30 \mathrm{~min}$ at $120^{\circ} \mathrm{C}$. The reaction mixture was allowed to cool to room temperature and the solvent was removed under reduced pressure. Then $\mathrm{MeCN}(30 \mathrm{~mL}$ ) was added to the residue and stirred for $0.5 \mathrm{~h}$. The solid was collected by filtration, washed with further MeCN and dried in air. Crystals suitable for $\mathrm{X}$-ray structure studies were obtained by slow evaporation from a mixture of $\mathrm{Et}_{2} \mathrm{O}-\mathrm{MeCN}$.

Yield: $0.38 \mathrm{~g}, 66 \%$ based on Th. Elemental analysis calculated (\%) for $\mathrm{Th}_{2} \mathrm{Cr}_{6} \mathrm{~F}_{12} \mathrm{C}_{96} \mathrm{H}_{186} \mathrm{O}_{33} \mathrm{~N}_{2}$ : Th 15.77, $\mathrm{Cr} 10.60, \mathrm{C} 39.75, \mathrm{H} 6.46, \mathrm{~N}$ 0.97; found (\%) Th 16.15, Cr 10.57, C 39.08, H 6.26, N 0.85 .

\section{$\left[{ }^{n} \mathrm{Pr}_{2} \mathrm{NH}_{2}\right]\left[\mathrm{Cr}_{6} \mathrm{U}_{2} \mathrm{O}_{2} \mathrm{~F}_{8}\left(\mathrm{O}_{2} \mathrm{C}^{t} \mathrm{Bu}\right)_{16}\left(\mathrm{Me}_{2} \mathrm{SO}\right)\right], 6$}

$\left[\mathrm{U}_{4} \mathrm{O}_{2}\left(\mathrm{O}_{2} \mathrm{C}^{\mathrm{t}} \mathrm{Bu}\right)_{12}\right](0.234 \mathrm{~g}, 0.1 \mathrm{mmol})$, pivalic acid $(0.2 \mathrm{~g}, 2.0$ $\mathrm{mmol})$, DMSO (1.0 g) and $\left[\left({ }^{n} \mathrm{Pr}_{2} \mathrm{NH}_{2}\right)_{3}\left\{\mathrm{Cr}_{6} \mathrm{~F}_{11}\left(\mathrm{O}_{2} \mathrm{CtBu}\right)_{10}\right\}\right]_{2}(0.268$ $\mathrm{g}, 0.075 \mathrm{mmol})$ were dissolved in toluene $(20 \mathrm{~mL})$ and refluxed with stirring for $30 \mathrm{~min}$ at $120 \circ \mathrm{C}$. The reaction mixture was allowed to cool to room temperature and the solvent was removed under reduced pressure. Then $\mathrm{MeCN}(30 \mathrm{~mL})$ was added to the residue and stirred for $0.5 \mathrm{~h}$. The green solid was collected by filtration, washed with further MeCN and dried in vacuo. The solid was then extracted with a mixture of $\mathrm{Et}_{2} \mathrm{O}-$ MeCN (1:1, $5 \mathrm{~mL})$, reduced in volume to ca. $2 \mathrm{~mL}$, and stored at - $10{ }^{\circ} \mathrm{C}$ to give 3 as green blocks.

Yield: $0.51 \mathrm{~g}, 36 \%$ based on $\mathrm{U}$. Elemental analysis calculated (\%) for $\mathrm{U}_{2} \mathrm{Cr}_{6} \mathrm{~F}_{8} \mathrm{C}_{88} \mathrm{H}_{166} \mathrm{O}_{35} \mathrm{~N}_{1}$ : U 17.18, $\mathrm{Cr} 11.26, \mathrm{C} 38.15, \mathrm{H}$ 6.04, $\mathrm{N}$ 0.51; found (\%) U 17.45, Cr 11.26, C, 38.92, H 6.09, N 0.91.

\section{Crystallography}

\section{Data Collection}

Single crystal X-ray diffraction data were collected for the crystal structures $\mathbf{2}$ and $\mathbf{3}$ at a temperature of $150 \mathrm{~K}$ using MoKa radiation, $(\lambda=0.71073 \AA)$ on an Oxford $X^{\prime}$ calibur diffractometer, equipped with an Atlas CCD detector and an Oxford Cryojet nitrogen flow gas system. Data was measured using CrysAlisPro suite of programs. X-ray data for compound 4 were collected at a temperature of $150 \mathrm{~K}$ using $\mathrm{MoK}_{\alpha}$ radiation, $(\lambda=0.71073 \AA$ A $)$ on an Agilent Technologies Supernova diffractometer equipped with an Eos CCD detector and an Oxford Cryostream 700 nitrogen flow gas system. X-ray data for compounds 5 and 6 were collected at a temperature of $150 \mathrm{~K}$ using $\mathrm{CuK}_{\alpha}$ radiation $(\lambda=1.54184 \AA$ ) on an Bruker $\mathrm{X} 8$ prospector diffractometer equipped with an Apex II CCD detector and an Oxford Cryostream 700 nitrogen flow gas system.

\section{Crystal structure determinations and refinements.}

X-ray data for crystals 2, 3, 4 and 5 were processed and reduced using CrysAlisPro suite of programs. Absorption correction was performed using empirical methods based upon symmetry-equivalent reflections combined with measurements at different azimuthal angles using SCALE3 ABSPACK. X-ray data for crystal 6 were processing using Bruker SAINT and absorption correction was performed using empirical methods based upon symmetry-equivalent reflections combined with measurements at different azimuthal angles using Bruker SADABS. The crystal structures for all were solved and refined against all $\mathrm{F}^{2}$ values using SHELX-2016 implemented through Olex2 v1.2.8. ${ }^{9}$ All non$\mathrm{H}$ atoms were refined anisotropically, with the exceptions of the carbon atoms corresponding to disordered solvent toluene molecules. Hydrogen atoms were placed in calculated positions refined using idealized geometries (riding model) and assigned fixed isotropic displacement parameters. Occupancies of the Chromium and Titanium atoms were fixed to a 7:1 and 3:1 ratio in crystals $\mathbf{2}$ and $\mathbf{3}$, respectively. The position and atomic displacement parameters were constrained to be equal using EXYZ and EADP commands. Occupancy of the bridging fluorides and oxides were set to have 3:1 and 5:3 proportions in crystals 2 and 3, respectively. The atomic displacement parameters were constrained to be equal using EADP command. Pivalate ligands in all the crystal structures were disordered and modelled over two positions where possible. Same distance and fixed distance restraints were applied to restrain some of the C$C$ bonds. Similar neighbouring atomic displacement parameter (apd) and rigid bond restraints, and in some cases isotropic adp restraints were used to restrain the apds.

\section{Physical measurements}

Variable temperature and field-dependent magnetic moment data were recorded on a Quantum Design MPMS XL7 SQUID magnetometer. To avoid sample reorientation during measurements, ground samples were fixed with a known amount of eicosane. Diamagnetic corrections were applied using tabulated Pascal constants and measurements were corrected for the effect of the blank sample holders (straw or flame sealed Wilmad NMR tube) and eicosane.

Continuous wave EPR spectra were recorded at Q-band (ca. $34 \mathrm{GHz}$ ) using a spectrometer equipped with a Bruker EMX EPR console, a 1.8 T magnet and a Bruker ER051 QG microwave bridge with an ER 5106 QT ( $Q$ band) resonator. The data were collected on polycrystalline powders grounded with eicosane at variable low temperatures (using a liquid He Oxford Cryostat). 
Table 1. Crystallographic information for compounds 2 - 6 .

\begin{tabular}{|c|c|c|c|c|c|}
\hline & 2 & 3 & 4 & 5 & 6 \\
\hline Identification code & orepw1860_Cr7Ti & orepw1883_Cr6Ti2 & adpm291 Cr6Th & xadpm45 Cr6Th2 & Xrepw772 Cr6U2 \\
\hline Empirical formula & $\mathrm{C}_{88} \mathrm{H}_{165} \mathrm{Cr}_{7} \mathrm{~F}_{6} \mathrm{NO}_{34.5} \mathrm{Ti}$ & $\mathrm{C}_{93} \mathrm{H}_{168} \mathrm{Cr}_{6} \mathrm{~F}_{5} \mathrm{NO}_{35} \mathrm{Ti}_{2}$ & $\mathrm{C}_{90} \mathrm{H}_{165} \mathrm{Cr}_{6} \mathrm{~F}_{7} \mathrm{~N}_{2} \mathrm{O}_{34} \mathrm{STh}$ & $\mathrm{C}_{96} \mathrm{H}_{186} \mathrm{Cr}_{6} \mathrm{~F}_{12} \mathrm{~N}_{2} \mathrm{O}_{33} \mathrm{Th}_{2}$ & $\mathrm{C}_{102} \mathrm{H}_{182} \mathrm{Cr}_{6} \mathrm{~F}_{8} \mathrm{NO}_{35} \mathrm{SU}_{2}$ \\
\hline $\mathrm{Mr}$ & 2315.10 & 2363.07 & 2528.33 & 2900.54 & 2954.60 \\
\hline Crystal system & monoclinic & monoclinic & monoclinic & monoclinic & orthorhombic \\
\hline Space group & $\mathrm{P}_{1} / \mathrm{c}$ & $\mathrm{P} 2_{1} / \mathrm{c}$ & $\mathrm{P} 2_{1} / \mathrm{c}$ & $\mathrm{P} 2_{1} / \mathrm{n}$ & $\mathrm{P} 2_{1} 2_{1} 2$ \\
\hline$a / A ̊$ & $25.3319(14)$ & $25.0563(18)$ & $35.4782(4)$ & $17.7566(3)$ & $33.1772(7)$ \\
\hline $\mathrm{b} / \AA ̊$ & $16.6836(8)$ & $16.9637(14)$ & $29.7042(3)$ & $42.1752(6)$ & $32.7339(8)$ \\
\hline$c / \AA ̊$ & $31.1000(14)$ & $31.2329(18)$ & $24.7842(4)$ & $18.6391(3)$ & $13.1235(3)$ \\
\hline$\alpha /^{\circ}$ & 90 & 90 & 90 & 90 & 90 \\
\hline$\beta /^{\circ}$ & $99.847(5)$ & $99.553(5)$ & $105.4775(14)$ & $103.033(2)$ & 90 \\
\hline$\gamma /{ }^{\circ}$ & 90 & 90 & 90 & 90 & 90 \\
\hline Volume $/ \AA^{3}$ & $12950.0(11)$ & $13091.3(16)$ & $25171.6(6)$ & $13599.0(4)$ & $14252.4(6)$ \\
\hline $\mathrm{Z}$ & 4 & 4 & 8 & 4 & $\mathrm{P} 2_{1} 2_{1} 2$ \\
\hline$\rho_{\text {calc }} \mathrm{g} / \mathrm{cm}^{3}$ & 1.187 & 1.199 & 1.334 & 1.417 & $33.1772(7)$ \\
\hline Temperature/K & 150.15 & 150.15 & $150.02(10)$ & $150.00(2)$ & $150.00(2)$ \\
\hline$\mu / \mathrm{mm}^{-1}$ & 0.695 & 0.666 & 1.769 & 11.429 & 10.689 \\
\hline Goodness-of-fit on $\mathrm{F}^{2}$ & 1.028 & 1.086 & 1.014 & 1.110 & 1.039 \\
\hline Final $R$ indexes $[\mid>=2 \sigma(I)]$ & $R_{1}=0.0960, w R_{2}=0.2603$ & $\mathrm{R}_{1}=0.1253, \mathrm{wR}_{2}=0.2418$ & $\mathrm{R}_{1}=0.0578, \mathrm{wR}_{2}=0.1122$ & $R_{1}=0.0792, w R_{2}=0.1818$ & $R_{1}=0.0876, w R_{2}=0.2226$ \\
\hline Final $\mathrm{R}$ indexes [all data] & $R_{1}=0.1757, w R_{2}=0.3268$ & $\mathrm{R}_{1}=0.2125, \mathrm{wR}_{2}=0.2837$ & $R_{1}=0.1093, w R_{2}=0.1343$ & $R_{1}=0.0904, w R_{2}=0.1888$ & $R_{1}=0.1202, w R_{2}=0.2549$ \\
\hline$F(000)$ & 4880.0 & 4984.0 & 10432.0 & 5888.0 & 5988.0 \\
\hline Crystal size $/ \mathrm{mm}^{3}$ & $0.65 \times 0.3 \times 0.3$ & $0.65 \times 0.3 \times 0.2$ & $0.303 \times 0.245 \times 0.109$ & $0.04 \times 0.03 \times 0.02$ & $0.2 \times 0.2 \times 0.2$ \\
\hline Radiation & $\operatorname{MoK} \alpha(\lambda=0.71073)$ & $\operatorname{MoK} \alpha(\lambda=0.71073)$ & $\operatorname{MoK} \alpha(\lambda=0.71073)$ & $\operatorname{CuK} \alpha(\lambda=1.54184)$ & $\operatorname{CuK} \alpha(\lambda=1.54184)$ \\
\hline $2 \Theta$ range for data collection $/^{\circ}$ & 6.884 to 52.744 & 6.938 to 50.7 & 4.812 to 52.744 & 5.298 to 150.118 & 2.662 to 139.384 \\
\hline Index ranges & $\begin{array}{c}-31 \leq h \leq 31,-18 \leq k \leq 20 \\
-33 \leq 1 \leq 38\end{array}$ & $\begin{array}{c}-24 \leq h \leq 30,-17 \leq k \leq 20 \\
-37 \leq 1 \leq 27\end{array}$ & $\begin{array}{c}-29 \leq h \leq 44,-37 \leq k \leq 34 \\
-30 \leq 1 \leq 28\end{array}$ & $\begin{array}{c}-22 \leq h \leq 20,-49 \leq k \leq 52 \\
-22 \leq 1 \leq 22\end{array}$ & $\begin{array}{c}-39 \leq h \leq 39,-39 \leq k \leq 37 \\
-15 \leq 1 \leq 15\end{array}$ \\
\hline Reflections collected & 61269 & 49742 & 88604 & 117174 & 105200 \\
\hline Independent reflections & $\begin{array}{c}26204\left[R_{\text {int }}=0.0591\right. \\
\left.R_{\text {sigma }}=0.1017\right]\end{array}$ & $\begin{array}{c}23853\left[R_{\text {int }}=0.0641\right. \\
\left.R_{\text {sigma }}=0.1319\right]\end{array}$ & $\begin{array}{c}51081\left[R_{\text {int }}=0.0387,\right. \\
\left.R_{\text {sigma }}=0.0846\right]\end{array}$ & $\begin{array}{c}27102\left[R_{\text {int }}=0.0976\right. \\
\left.R_{\text {sigma }}=0.0557\right]\end{array}$ & $\begin{array}{c}25941\left[R_{\text {int }}=0.1236\right. \\
\left.R_{\text {sigma }}=0.1132\right]\end{array}$ \\
\hline $\begin{array}{l}\text { Data/restraints/ } \\
\text { parameters }\end{array}$ & $26204 / 2263 / 1280$ & $23853 / 904 / 1470$ & $51081 / 8175 / 3186$ & $27102 / 4655 / 2020$ & $25941 / 4230 / 1557$ \\
\hline
\end{tabular}

${ }^{\mathrm{a}} R 1(F)=\Sigma\left(\left|F_{o}\right|-\left|F_{c}\right|\right) / \Sigma\left|F_{o}\right| ;[\mathrm{b}] w R^{2}\left(F^{2}\right)=\left[\Sigma w\left(F_{o}{ }^{2}-F_{c}{ }^{2}\right)^{2} / \Sigma w F_{o}{ }^{4}\right]^{1 / 2} ;[\mathrm{c}] S\left(F^{2}\right)=\left[\Sigma w\left(F_{o}{ }^{2}-F_{c}{ }^{2}\right)^{2} /(n+r-p)\right.$ 


\section{Results and discussion}

\section{Syntheses and structures}

Initially, we studied the binding of $\left[\left({ }^{\mathrm{n}} \mathrm{Pr}_{2} \mathrm{NH}_{2}\right)_{3}\left\{\mathrm{Cr}_{6} \mathrm{~F}_{11}\left(\mathrm{O}_{2} \mathrm{C}^{\mathrm{t}} \mathrm{Bu}\right)_{10}\right\}\right]_{2}$, $\mathbf{1}$, to group (IV) transition metal metals, reasoning that these analogues would mimic thorium(IV) chemistry, as the +4 oxidation state predominates for thorium. The reaction of 1 with $\mathrm{Ti}(\mathrm{acac})_{4}$ resulted in the formation of $\left[{ }^{\mathrm{n}} \mathrm{Pr}_{2} \mathrm{NH}_{2}\right]\left[\mathrm{Cr}_{7} \mathrm{TiF}_{6} \mathrm{O}_{2}\left(\mathrm{O}_{2} \mathrm{C}^{\mathrm{t}} \mathrm{Bu}\right)_{16}\right] 2$ (Figure 1).
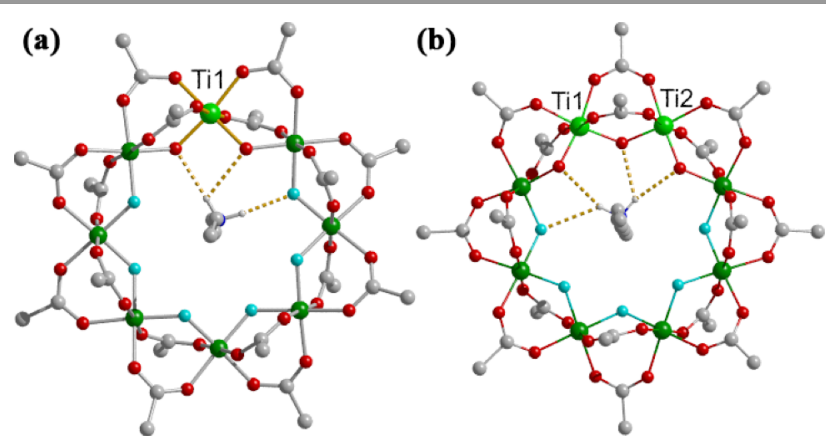

Figure 1. The crystal structure of (a) 2, (b) 3. Methyl groups of pivalates and solvent molecules omitted for clarity. Colours: $\mathrm{Cr}$, green; $\mathrm{Ti}$, light green; $\mathrm{O}$, red; $\mathrm{F}$, turquoise; N, blue; C, grey.

The structure of 2 consists of an octametallic ring, bridged internally by two $\mu_{2}$-oxide and six $\mu_{2}$-fluoride anions, with each $\mathrm{M}$...M edge further bridged on the periphery by two pivalate ligands (Figure 1). The $\mathrm{Ti}^{\mathrm{IV}}$ ion cannot be localised within the structure and is modelled as disordered over eight metal sites. This is a common feature for $\left\{\mathrm{Cr}_{7} \mathrm{M}\right\}$ rings, where $\mathrm{M}$ adopts an octahedral geometry. ${ }^{2}$ As the $\mathrm{Ti}^{\mathrm{IV}}$ sites are disordered, so are the bridging anions; charge balance require two oxides to be present as $\mu_{2}$-bridges, which are probably localised on the $\mathrm{Cr}$...Ti edges, while the fluorides bridge the $\mathrm{Cr}$...Cr edges.

If $\mathrm{a}\left\{\mathrm{Ti}_{8}\right\}$ ring $^{9}$ is used as the starting material, we form $\left[{ }^{\mathrm{n}} \mathrm{Pr}_{2} \mathrm{NH}_{2}\right]\left[\mathrm{Cr}_{6} \mathrm{~F}_{5} \mathrm{Ti}_{2} \mathrm{O}_{3}\left(\mathrm{O}_{2} \mathrm{C} \mathrm{C}^{\mathrm{t}} \mathrm{Bu}\right)_{16}\right]$ 3. Again it is not possible to localize the $\mathrm{Ti}^{\mathrm{IV}}$ sites in the crystal structure of $\mathbf{3}$, which generates the possibility of structural isomers. Given the other chemistry we have seen starting with $\mathbf{1}$ we believe it most likely that the two $\mathrm{Ti}^{\mathrm{iV}}$ ions neighbour each other in the structure. Electrospray mass spectrometry confirms the constitution of these structurally analogous clusters, with $\mathbf{2}$ and $\mathbf{3}$ giving distinct positive ion peaks by electrospray mass spectrometry (Figures $\mathrm{S} 1$ and $\mathrm{S} 2,\left[\left\{\mathrm{Cr}_{7} \mathrm{Ti}\right\}+\mathrm{Na}\right]^{+}:+2300$ and $\left.\left[\left\{\mathrm{Cr}_{6} \mathrm{Ti}_{2}\right\}+\mathrm{Na}\right]^{+}:+2293\right)$.

The severe positional disorder in these structures makes any analysis of metric parameters impossible; the necessary restraints imposed on the crystallographic model preclude this. Attempts were also made to combine 1 and precursors of $Z r^{\mathrm{IV}}$ and $\mathrm{Hf}^{\mathrm{IV}}$, but no crystalline product was obtained.

The reaction of 1 with $\left[\mathrm{Th}\left(\mathrm{O}_{2} \mathrm{C}^{\mathrm{t}} \mathrm{Bu}\right)_{4}\right]$ in THF/MeCN at room temperature with the presence of DMSO resulted in the formation of a $\left\{\mathrm{Cr}_{6} \mathrm{Th}\right\}$ ring $\left[\mathrm{Cr}_{6} \mathrm{ThF}_{7}\left(\mathrm{O}_{2} \mathrm{C}^{\mathrm{t}} \mathrm{Bu}\right)_{15}\left(\mathrm{Me}_{2} \mathrm{SO}\right)\right] \mathbf{4}$ (Figure 2a). Complex 4 crystalizes with two heptametallic rings in the asymmetric unit. Each ring contains one $\mathrm{Th}^{\mathrm{IV}}$ and six $\mathrm{Cr}^{\mathrm{III}}$ ions with each edge of the ring bridged by a fluoride and two pivalates. The $T h^{\mathrm{IV}}$ site is nine-coordinate with a terminal coordinated DMSO and a chelating pivalate. Two MeCN molecules lie on each side of the ring forming $\mathrm{C}-\mathrm{H} \cdots \mathrm{F}$ hydrogen bonds with the fluorides in the cavity of the ring. The $\mathrm{C} \cdots \mathrm{F}$ distances are between 3.076(4) - 3.573(2) $\AA$ and are thus in the range as many other reported $\mathrm{C}-\mathrm{H} \cdots \mathrm{F}$ hydrogen bonds. ${ }^{10}$ Performing the reaction with the same reaction mixture in refluxing toluene results in a $\left\{\mathrm{Cr}_{6} \mathrm{Th}_{2}\right\}$ ring $\left[\left({ }^{\mathrm{n}} \mathrm{Pr}_{2} \mathrm{NH}_{2}\right)_{2}\left(\mathrm{Cr}_{6} \mathrm{Th}_{2} \mathrm{~F}_{12}\left(\mathrm{O}_{2} \mathrm{C}^{\mathrm{t}} \mathrm{Bu}\right)_{16}\right)\right] \mathbf{5}$ (Figure 2b). Complex $\mathbf{5}$ contains an octametallic ring $\left\{\mathrm{Cr}_{6}^{\mathrm{III}}{ }_{6} \mathrm{Th}^{\mathrm{IV}}{ }_{2}\right\}$. Each $\mathrm{Cr}$... Cr and $\mathrm{Cr}$...Th edge is bridged by a fluoride and two pivalates. The unique Th....Th edge is bridged by three fluorides. Each Th site is ninecoordinate with a terminal fluoride and a chelating pivalate complementing the bridging ligands. The Th- $F$ bond lengths (with an average value of $2.393 \AA$ for bridging fluorides and $2.210 \AA$ for terminal ones) are relatively shorter than the Th-O bond lengths (with an average value of $2.481 \AA$ ). There are two protonated amide countercations $\left({ }^{n} \mathrm{Pr}_{2} \mathrm{NH}_{2}\right)$ in the asymmetric unit. One of lies within the ring, forming many $\mathrm{N}-\mathrm{H} \cdots \mathrm{F}$ and $\mathrm{C}$ -
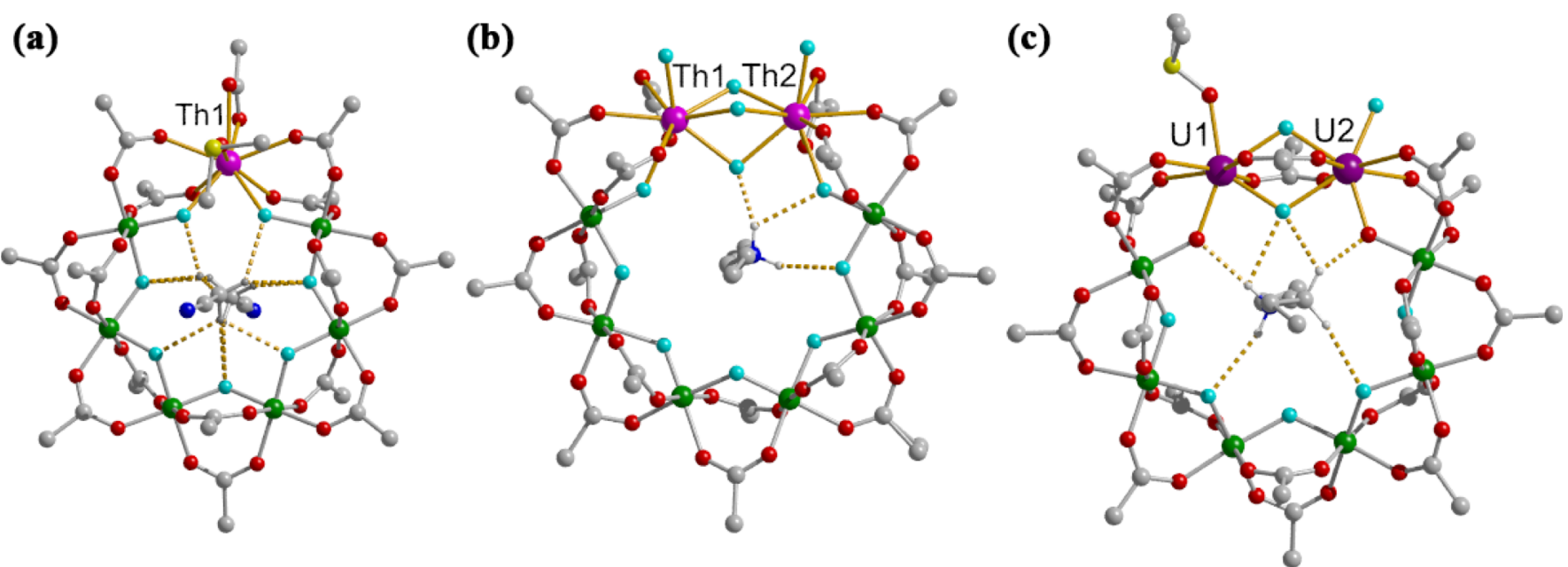

Figure 2. The crystal structure of (a) 4, (b) 5, and (c)6, Methyl groups of pivalates and solvent molecules omitted for clarity. Colours: Cr, green; O, red; F, turquoise; N, blue; Th, pink; U, violet; $S$, yellow; $C$, grey. 
$\mathrm{H} \cdots \mathrm{F}$ hydrogen bonds with the fluorides. The second is outside the ring, forming $\mathrm{N}-\mathrm{H} \cdots \mathrm{F}$ hydrogen bonds to terminal fluorides. The structures of $\mathbf{4}$ and $\mathbf{5}$ are similar to those previously reported in reactions between $\left\{\mathrm{Cr}_{6}\right\}$ horseshoes and lanthanides. 4 is similar to the $\left[\left(\mathrm{Cr}_{6} \mathrm{CeF}_{7}\left(\mathrm{O}_{2}{ }^{\mathrm{t}} \mathrm{Bu}\right)_{14}(\mathrm{THF})_{2}\right]\right.$ ring, ${ }^{4}$ and is a rare example of a heptametallic ring. ${ }^{11}$ The $\mathrm{Th}^{\mathrm{IV}}$ ring differs from the $\mathrm{Ce}^{\mathrm{III}}$ ring in the ligands attached to the f-block metal; for $\mathrm{Th}^{\mathrm{IV}}$ a chelating pivalate and a DMSO occupy positions taken by two THF molecules on the $\mathrm{Ce}^{\text {III }}$ site. $\mathbf{5}$ is similar to the previously reported $\left[\left(\mathrm{Et}_{2} \mathrm{NH}_{2}\right)\left(\mathrm{Cr}_{6} \mathrm{Y}_{2} \mathrm{~F}_{8}\left(\mathrm{O}_{2} \mathrm{CtBu}\right)_{17}\left(\mathrm{H}_{2} \mathrm{O}\right)\right]\right.$. ${ }^{4}$ The differences between these eight membered rings are in the $\mathrm{f}$ block metals; for $\left\{\mathrm{Cr}_{6} \mathrm{Y}_{2}\right\}$ the two $\mathrm{Y}^{\prime \prime \prime}$ are bridged by a fluoride and three pivalates and $Y$ sites are eight-coordinate.

The change in the number of $\mathrm{f}$-block metal ions incorporated in the structures of $\mathbf{4}$ and $\mathbf{5}$ mirrors results previously observed in the synthesis of $\left\{\left(\mathrm{Cr}_{6}\right)_{2} \mathrm{Gd}_{\mathrm{x}}\right\}$ ( $\mathrm{x}=2$ or 4 ) compounds. ${ }^{4}$ In that case, the reaction of $\left\{\mathrm{Cr}_{6}\right\}_{2}$ and $\left[\mathrm{Gd}\left(\mathrm{O}_{2} \mathrm{C}^{\mathrm{t}} \mathrm{Bu}\right)_{3}\left(\mathrm{HO}_{2} \mathrm{C}^{\mathrm{t}} \mathrm{Bu}\right)_{3}\right]_{2}$ in $\mathrm{THF} / \mathrm{MeCN}$ with the presence of DMSO at room temperature led to $\left\{\left(\mathrm{Cr}_{6}\right)_{2} \mathrm{Gd}_{2}\right\}$ and produced $\left\{\left(\mathrm{Cr}_{6}\right)_{2} \mathrm{Gd}_{4}\right\}$ in refluxing toluene. In both cases the reactions at higher temperatures results in the $\left\{\mathrm{Cr}_{6}\right\}$ chains binding a greater number of metal ions.

Attempts to make an analogous starting material with $\mathrm{U}(\mathrm{IV})$, $\left[\mathrm{U}\left(\mathrm{O}_{2} \mathrm{C}^{\mathrm{t}} \mathrm{Bu}\right)_{4}\right]$, resulted instead in the formation of a tetrametallic $U^{\mathrm{IV}}$ cage, $\left[\mathrm{U}_{4} \mathrm{O}_{2}\left(\mathrm{O}_{2} \mathrm{C}^{\mathrm{t}} \mathrm{Bu}\right)_{12}\right]$ and a direct analogue could not be produced. Therefore, we used this cage as a starting material. These resulted in the formation of $\left.\left[{ }^{n} \mathrm{Pr}_{2} \mathrm{NH}_{2}\right]\left[\mathrm{Cr}_{6} \mathrm{U}_{2} \mathrm{~F}_{8} \mathrm{O}_{2}\left(\mathrm{O}_{2} \mathrm{C}^{t} \mathrm{Bu}\right)_{16}\right)\left(\mathrm{Me}_{2} \mathrm{SO}\right)\right]$, 6. The structure differs significantly from $\mathbf{5}$ (Figure 2c). A complication in preparing the crystallographic model arises from the potential presence of two monoatomic ligands - fluoride and oxide with a metal that can vary oxidation state. Here we report the result we believe most likely based on metric parameters and refined thermal parameters, but clearly other alternatives are possible which would then change the oxidation states of the uranium centres.

The U....U edge is bridged by two fluorides (average U-F bond length $2.330 \AA$ ) and two pivalates. This implies there two eight-coordinated $U$ sites with differing oxidation states, based on the charge balance of the complex, one being a $U^{v}$ ion and the other a $U^{\mathrm{IV}}$ ion. Both $U$ sites are bridged to $\mathrm{Cr}$ through oxides (2.200 $\AA$ average $\mathrm{U}-\mathrm{O}_{\text {bridging }}$ bond length). These $\mathrm{U}$-O bond are significantly shorter than the average U-O-M bridging oxide distances fond in the CSD (mean U-O distances for $\mu_{2}$-oxide bridging to other metals $=2.32(16) \AA$ ). There are no U-F-M distances in the CSD with which to compare.

Structurally characterised examples of actinides bridged by three $\mu$-fluorides have been reported previously, ${ }^{12-14}$ mainly in coordination polymers. The two zero-dimensional examples are $\left(\mathrm{C}_{5} \mathrm{~N}_{2} \mathrm{H}_{14}\right)_{2}\left(\mathrm{H}_{3} \mathrm{O}\right)\left[\mathrm{U}_{2} \mathrm{~F}_{13}\right]^{13}$ with a dimeric $\left[\mathrm{U}_{2} \mathrm{~F}_{13}\right]^{5-}$ unit reported by the O'Hare group and an organometallic complex $\left[\mathrm{Th}_{2} \mathrm{~F}_{5}(1,3-\right.$ $\left.\left(\mathrm{Me}_{3} \mathrm{C}\right)_{2} \mathrm{C}_{5} \mathrm{H}_{3}\right)_{2}$ (bipy) $]^{14}$ reported by $\mathrm{Zi}$ and Walter. There is some analogy between $\mathbf{5}$ and the structures found when $\mathbf{1}$ is reacted with lanthanides; instead of the formation of the $A n_{2} F_{3}$ unit the lanthanides tend to form a dimer of the structure of $\mathbf{5}$ with a central $\mathrm{Ln}_{4} \mathrm{~F}_{7}$ cage. ${ }^{4}$

In complexes 2-5, the $\left\{\mathrm{Cr}_{6}\right\}$ chain binds with the same mode as previously seen in other compounds formed by reaction of horseshoes, with one fluoride and two pivalates binding to the heterometal at each edge of the chain. Two of the three terminal fluorides on each terminal $\mathrm{Cr}^{\text {III }}$ site are displaced by pivalates, while the other one is retained. The $\mathrm{Cr} \cdots \mathrm{Cr}$ distances and $\mathrm{Cr}-\mathrm{F}-\mathrm{Cr}$ angles in complexes 4-5 are comparable to those in the chain 1 , indicating the chain's robustness. The chains are further stabilized by metal-bonded fluorides which are good acceptors and can form strong hydrogen bondings. ${ }^{12}$ Compound $\mathbf{6}$ is an anomaly in these systems with the potential oxide bridging, assuming the oxidation states of the uranium sites are correct.

\section{SQUID Magnetometry}

Variable-temperature magnetic susceptibilities were recorded in an applied dc field of $0.1 \mathrm{~T}$ and $0.5 \mathrm{~T}$ for compounds $\mathbf{2}-\mathbf{6}$ to study the effect of the $M^{\mathrm{IV}}$ ions to the magnetic exchange pathways of the $\mathrm{Cr}_{x}$ chains.

The plots of molar magnetic susceptibility $\left(\chi_{M}\right.$ and $\left.\chi_{M} T\right)$ of the five compounds are similar, indicating antiferromagnetic intra-molecule exchanges. All the data for $\mathbf{2}$ - $\mathbf{5}$ were fitted $^{15}$ with a simple isotropic exchange Hamiltonian, where $J_{1}$ and $J_{2}$ are the terminal and internal $\mathrm{Cr}-\mathrm{Cr}$ exchange coupling constants within the $(n+m)$ - membered rings, with $n=$ number of paramagnetic metal ions:

$$
\begin{gathered}
\widehat{H}=-2 J_{1}\left(\widehat{S}_{1} \cdot \widehat{S}_{2}+\widehat{S}_{n-1} \cdot \widehat{S}_{n}\right)-2 J_{2} \sum_{i=2}^{n-1} \widehat{S}_{i} \cdot \widehat{S}_{i+1}+\mu_{B} \\
\cdot \vec{B} \sum_{i=1}^{n} g_{i} \cdot \widehat{S}_{n}
\end{gathered}
$$
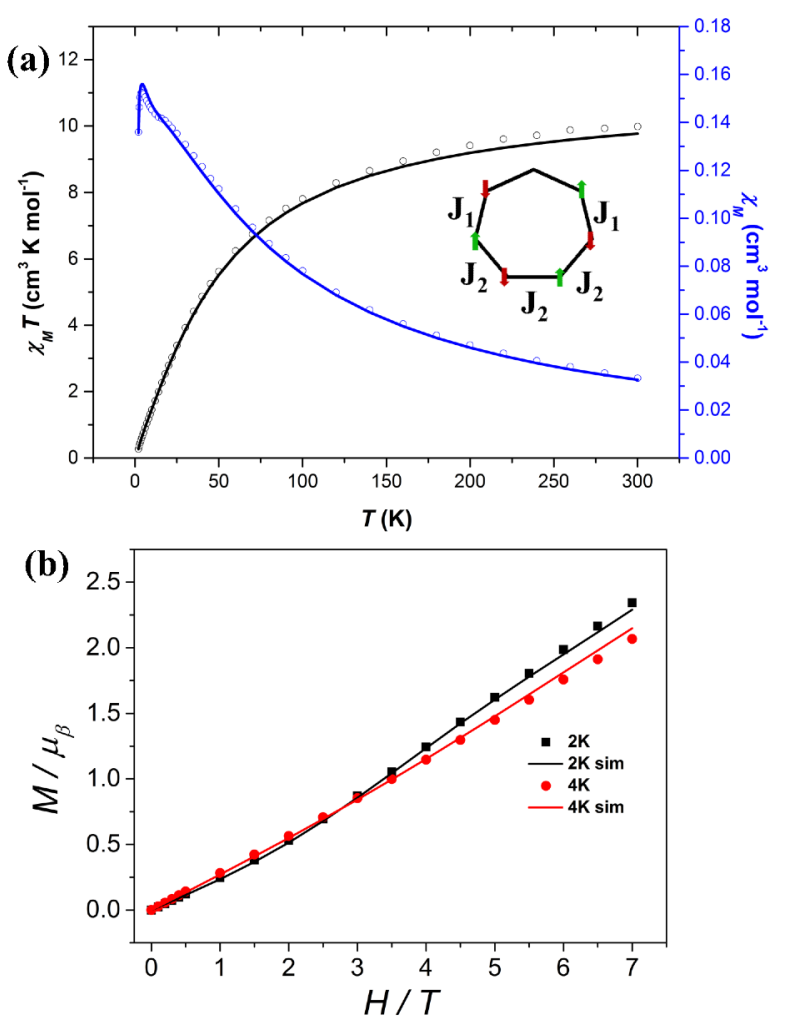

Figure 3. (a) Susceptibility vs. Temperature $\left(\chi_{M} T\right.$ vs. $T$, black circles and $\chi_{M}$ vs $T$, blue circles) and (b) Magnetization plots for 4 . Solid lines represent fittings, where $g_{c r}=1.98, J_{1}=-4.8 \mathrm{~cm}^{-1}$ and $J_{2}=-6.8 \mathrm{~cm}^{-1}$. An inset of the magnetic coupling model is included. 
In $\mathbf{2}$ - 5, the only paramagnetic centres present are within the $\left\{\mathrm{Cr}_{6}\right\}$ chain and the data can be fitted with $g_{c r}$ fixed at 1.98 allowing the exchange interactions to vary. The best fit parameters $\left(\right.$ in $\mathrm{cm}^{-1}$ ) are: for $2, J_{1}=J_{2}=-5.7$; for $3, J_{1}=-5.8, J_{2}=$ -5.3 ; for $4, J_{1}=-4.8, J_{2}=-6.8$; for $5, J_{1}=-5.3, J_{2}=-6.2 \mathrm{~cm}^{-1}$. (Figure $3 \mathrm{a}$ and Figure $\mathrm{S} 3$ ). We have previously observed variations of the two exchange interactions in $\mathrm{Cr}$-chains; ${ }^{16}$ here the variation seems to be dependent on the tetravalent metal present and the bridging atoms at the terminal $\mathrm{Cr}^{\mathrm{III}}$. For the two $\mathrm{Ti}^{\mathrm{IV}}$ rings the two exchange interactions are very similar. For the two $\mathrm{Th}^{\mathrm{IV}}$ rings, the internal $\mathrm{Cr}$...Cr exchange $\left(J_{2}\right)$ is larger than the terminal exchange.

The temperature dependence of $\chi_{M}$ for 6 is markedly different to that observed for 3-5 as might be expected as both $U^{V}$ and $U^{\mathrm{IV}}$ are paramagnetic (Figure 4). Quantifying the contribution of these ions is very difficult due to very large spinorbit coupling for actinides. ${ }^{17-19}$ It is possible to fit the magnetic data measured on 6 assuming a spin-only approximation and four different J-couplings accounting for the different metal pairs present in the ring $(\mathrm{Cr} \ldots . \mathrm{Cr}, \mathrm{Cr} \ldots . \mathrm{U}$ and $\mathrm{U} \ldots . . \mathrm{U})$ giving $J_{\mathrm{Cr}-\mathrm{Cr}}=$ $-5.2 \mathrm{~cm}^{-1}, J_{1 \mathrm{Cr}-U}=-4.0 \mathrm{~cm}^{-1}, J_{2 \mathrm{Cr}-U}=+4.0 \mathrm{~cm}^{-1}$ and $J_{U-U}=+0.8 \mathrm{~cm}^{-1}$. (Figure S5). The "spin-only" approximation associated with most $3 \mathrm{~d}$ transition metals cannot be widely used and can act only as an estimation of the lower limit of exchange coupling between such ions. Whether the derived parameters have any physical meaning is doubtful.

Magnetization $(M)$ as a function of field $(H)$ was measured for 2, 4, 5 and 6 at 2.0 and $4.0 \mathrm{~K}$ (Figure 3b, 4b and Figure S4).

(a)

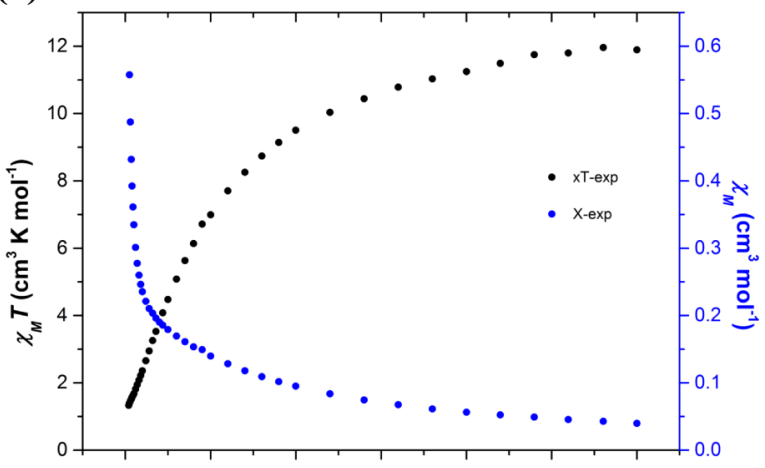

(b)

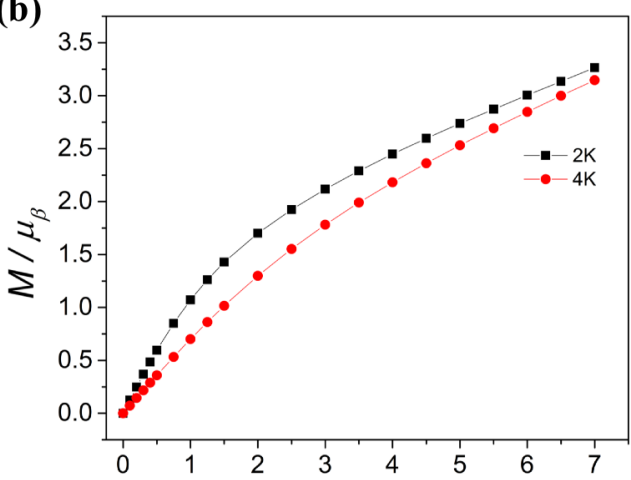

Figure 4. (a) Susceptibility vs. Temperature $\left(\chi_{M} T\right.$ vs. $T$, black circles and $\chi_{M}$ vs $T$, blue circles) and (b) Magnetization plots for $\mathbf{6}$. For the $\mathrm{MvH}$, lines are guides to the eye.
For 2, the magnetization saturates in accordance with a $S=3 / 2$ ground state at low temperature. For $\mathbf{4}$ and $\mathbf{5}$, the slow-increase in isothermal magnetization confirms the intramolecular antiferromagnetic coupling and $S=0$ ground state. The magnetization of $\mathbf{6}$ increases faster at low field than $\mathbf{4}$ and $\mathbf{5}$. This suggests 6 has a paramagnetic ground state.

\section{EPR Spectroscopy}

Variable temperature EPR spectra of compounds 2-5 were measured at Q-band (ca. $34 \mathrm{GHz}$ ). All compounds give rich and temperature-dependent EPR spectra below $20 \mathrm{~K}$. EPR simulations were performed with Easyspin ${ }^{20}$ using a strong exchange limit approximation where the EPR transitions occur within the thermally populated $S$ levels of the metal chain at a given temperature. ${ }^{21}$ Simulation of these individual states separately using axial $(D)$ and rhombic $(E)$ zero field splitting parameters followed by addition give a good agreement with the observed spectra (Figure 6 and 7). The spectrum of $\mathbf{2}$ (Figure 6a) has the same profile as $\left\{\mathrm{Cr}_{7} \mathrm{Cd}\right\}^{22}$ and $\left\{\mathrm{Cr}_{7} \mathrm{Zn}\right\}^{23}$ rings, with over $90 \%$ of the rings in the ground state $S=3 / 2$ at $5 \mathrm{~K}$ and the
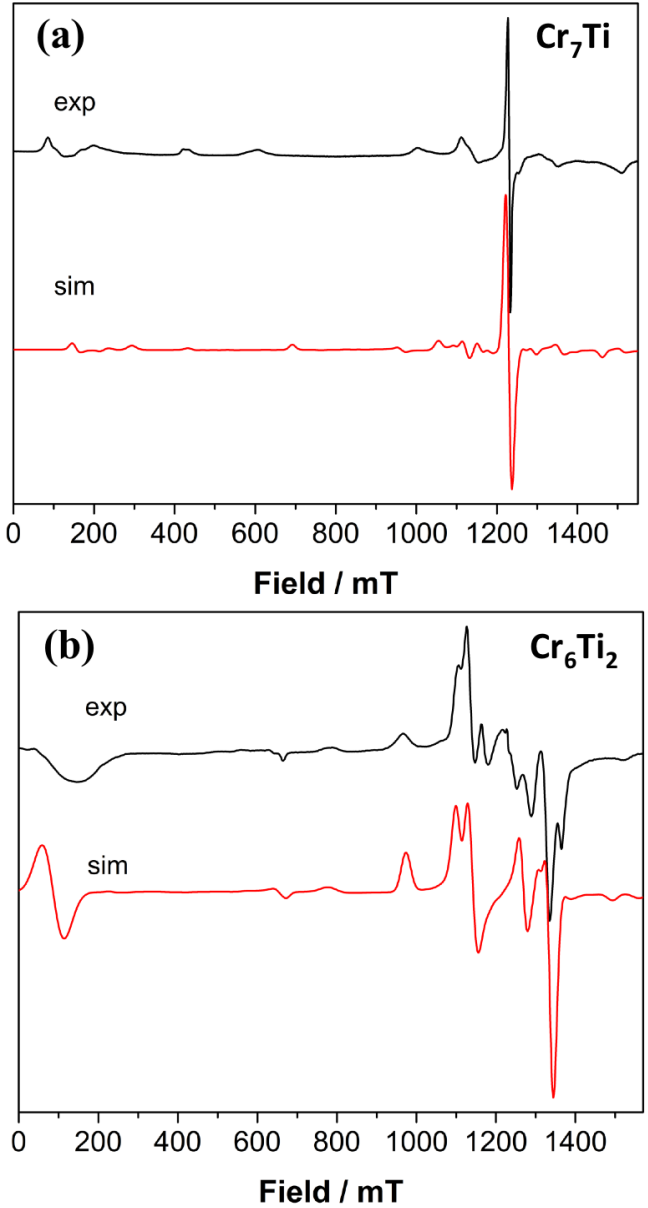

Figure 7. Experimental Q-band (ca. $34 \mathrm{GHz}$ ) EPR spectra and simulations (see main text and $\mathrm{SI}$ ) for (a) $\mathbf{2}$ at $34.0720 \mathrm{GHz}$ and (b) $\mathbf{3}$ at $33.9705 \mathrm{GHz}$ for powdered samples suspended in eicosane at $5 \mathrm{~K}$. Simulation parameters (with $g=1.98$ and Gaussian linewidth): for 2, $D_{S=3 / 2}=-0.419 \mathrm{~cm}^{-1}, E_{S=3 / 2}=0.0489 \mathrm{~cm}^{-1}(E / D=0.12)$, $D_{S=5 / 2}=0.066 \mathrm{~cm}^{-1}, E_{S=5 / 2}=0.0034 \mathrm{~cm}^{-1}(E / D=0.05)$ and $15 \mathrm{mT}$ linewidth; for $3, D_{S=1}=$ $-0.95 \mathrm{~cm}^{-1}, E_{S=1}=0.171 \mathrm{~cm}^{-1}\left(E / D=0.18,60 \mathrm{mT}\right.$ linewidth), $D_{S=2}=0.130 \mathrm{~cm}^{-1}, E_{S=2}=$ $0.013 \mathrm{~cm}^{-1}, B_{4}^{0}=4 \times 10^{-4} \mathrm{~cm}^{-1}(E / D=0.10,20 \mathrm{mT}$ linewidth $)$. 


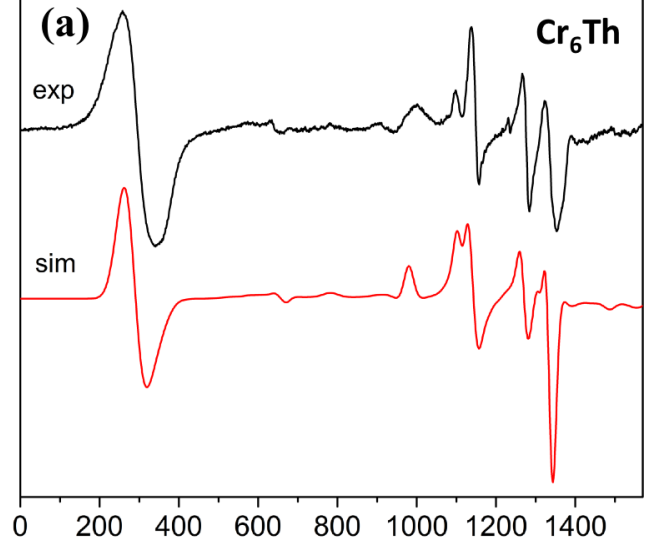

Field / mT

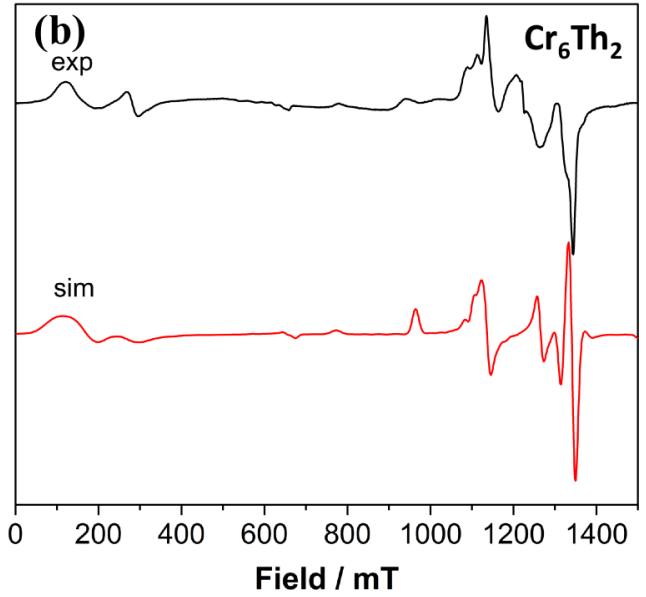

Figure 7. Experimental Q-band (ca. $34 \mathrm{GHz}$ ) EPR spectra and simulations (see main text) for (a) 4 at $34.1771 \mathrm{GHz}$ and (b) 5 at $34.1434 \mathrm{GHz}$ for powdered samples suspended in eicosane at $5 \mathrm{~K}$. Simulation parameters (with $g=1.98$ and Gaussian linewidth): for 4, $D_{S=1}=-0.81 \mathrm{~cm}^{-1}, E_{S=1}=0.186 \mathrm{~cm}^{-1}\left(E / D=0.23,60 \mathrm{mT}\right.$ linewidth), $D_{S=2}=0.129 \mathrm{~cm}^{-1}, E_{S=2}=$ $0.012 \mathrm{~cm}^{-1}, B_{4}^{0}=4 \times 10^{-4} \mathrm{~cm}^{-1}$ (E/D=0.09, 20mT linewidth); for 5, $g=1.98, D_{s=1}=-1.675 \mathrm{~cm}$ ${ }^{1}, E_{S=1}=0.553 \mathrm{~cm}^{-1}(E / D=0.33), D_{S=2}=0.134 \mathrm{~cm}^{-1}, E_{S=2}=0.0131 \mathrm{~cm}^{-1}, B_{4}^{0}=2.7 \times 10^{-4} \mathrm{~cm}^{-1}$ $(E / D=0.10,5 \% D$-strain) with a $60 \mathrm{mT}$ and $15 \mathrm{mT}$ linewidth respectively.

remaining features attributed to the first two excited states $(S=$ $1 / 2$ and $5 / 2$ ), thus it was simulated with similar parameters (Figure S7a).

Compounds 3, 4 and 5 (Figure 6 and 7) have $S=0$ ground states, and give similar EPR spectra. For all three compounds the majority of the observed resonances can be assigned to $S=1$ and $S=2$ excited states. The intensity of the low field peak is increased with lowering the temperature and this is assigned as the $\Delta m_{s}= \pm 2$ transition of a spin triplet state. The majority of the remaining features can be attributed to the $S=2$, the simulation of which required the addition of an axial fourth-order term $B_{4}^{0}$ for all compounds.

Some features around $1230 \mathrm{mT}$ in the spectra of $\mathbf{3}$ and $\mathbf{5}$ are not accounted for in the simulation and can be attributed to either the $S=3$ next excited state or, in the case of $\mathbf{3}$, to the presence of other linkage isomers that would generate a single $\mathrm{Cr}^{\mathrm{III}}$ or $\mathrm{Cr}_{5}$ chains. The former explanation seems more likely given their magnetic behaviour and the temperature dependence of their EPR spectra (Figure S6). The spectrum of compound 6 has a very broad feature at $g_{\text {eff }}=1.98$ and some very weak features appearing at higher temperatures (Figure S6d). Thus it is not possible to assign any spin states in the spectrum.

\section{Conclusions}

The chemistry of $\left\{\mathrm{Cr}_{6}\right\}$ horseshoe chains as ligands has been extended to actinides and $\mathrm{Ti}^{\mathrm{IV}}$. The reactions of the $\left\{\mathrm{Cr}_{6}\right\}$ chains 1 and precursors of actinides and group IV metals led to a series of rings $\left\{\mathrm{Cr}_{7} \mathrm{Ti}\right\}, \mathbf{2},\left\{\mathrm{Cr}_{6} \mathrm{Ti}_{2}\right\}, 3,\left\{\mathrm{Cr}_{6} \mathrm{Th}\right\}, \mathbf{4},\left\{\mathrm{Cr}_{6} \mathrm{Th}_{2}\right\}, \mathbf{5}$ and $\left\{\mathrm{Cr}_{6} \mathrm{U}_{2}\right\}$, 6. Complex 4 is a rare example of a heptametallic ring and is similar to $\left\{\mathrm{Cr}_{6} \mathrm{Ce}\right\} .5$ and $\mathbf{6}$ are eight membered rings similar to $\left\{\mathrm{Cr}_{6} \mathrm{Y}_{2}\right\}$. The $\left\{\mathrm{Cr}_{6}\right\}$ chains maintain their structures in these complexes and bind the tetravalent metals with same mode. This indicates that $\left\{\mathrm{Cr}_{6}\right\}$ chains can act as polydentate fluoride ligands for actinides and $\mathrm{Ti}^{\mathrm{IV}}$ to construct antiferromagnetic coupled heterometallic rings.

Their static magnetic properties were measured and fitted by isotropic exchange Hamiltonian. In accordance with $\mathbf{1}$, the magnetic exchanges between $\mathrm{Cr}^{\prime \prime \prime}$ are antiferromagnetic, while the exchange interactions can be modified by the tetravalent metals. For complex 6, ferromagnetic exchanges $J_{C r-U}$ and $J_{U-U}$ are obtained. EPR spectra of compounds 2-5 were measured at $\mathrm{Q}$-band and were simulated. The spectrum of $\mathbf{2}$ has the same profile as $\left\{\mathrm{Cr}_{7} \mathrm{Cd}\right\}$ and $\left\{\mathrm{Cr}_{7} \mathrm{Zn}\right\}$ rings with a ground state $S=3 / 2$. 3, $\mathbf{4}$ and $\mathbf{5}$ give similar EPR spectra with $S=0$ ground states.

\section{Conflicts of interest}

In accordance with our policy on Conflicts of interest please ensure that a conflicts of interest statement is included in your manuscript here. Please note that this statement is required for all submitted manuscripts. If no conflicts exist, please state that "There are no conflicts to declare".

\section{Acknowledgements}

This work was supported by the EPSRC (UK), by funding the National EPR Facility (EP/L018470/1) and an X-ray diffractometer (EP/K039547/1) and the University of Manchester. J.-D. Leng thanks the International Postdoctoral Exchange Fellowship Program of China and China Postdoctoral Science Foundation Funded Project (2014M552426) for funding.

\section{Notes and references}

¥ CCDC 1569554, 1569555, 1569557, 1813191 and 1813192 contain the supplementary crystallographic data for compounds $\mathbf{1}$ - $\mathbf{6}$. These data can be obtained free of charge via www.ccdc.cam.ac.uk/conts/retrieving.html (or from the Cambridge Crystallographic Data Centre, 12 Union Road, Cambridge CB21EZ, UK; fax: (+44)1223-336-033; or deposit@ccdc.cam.ac.uk). 
1 (a) F. Troiani, A. Ghirri, M. Affronte, S. Carretta, P. Santini, G. Amoretti, S. Piligkos, G. A. Timco and R. E. P. Winpenny, Phys. Rev. Lett., 2005, 94, 207208; (b) F. Troiani and M. Affronte, Chem. Soc. Rev., 2011,40, 3119-3129.

2 (a) G. A. Timco, T. B. Faust, F. Tuna, and R. E. P. Winpenny, Chem. Soc. Rev., 2011, 40, 3067-3075; (b) R. H. Laye, F. K. Larsen, J. Overgaard, C. A. Muryn, E. J. L. Mclnnes, E.Rentschler, V. Sanchez, S. J. Teat, H. U. Güdel, O. Waldmann, G. A. Timco and R. E. P.Winpenny, Chem. Commun., 2005, 1125-1127. (c) E. J. L. McInnes, G. A. Timco, G. F. S. Whitehead and R. E. P. Winpenny, Angew. Chem. Int. Ed., 2015, 54, 14244-14269.

3 M. Rancan, G. N. Newton, C. A. Muryn, R. G. Pritchard, G. A. Timco, L. Cronin and R. E. P. Winpenny, Chem. Commun., 2008, 1560-1562.

4 A. McRobbie, A. R. Sarwar, S. Yeninas, H. Nowell, M. L. Baker D. Allan, M. Luban, C. A. Muryn, R. G. Pritchard, R. Prozorov, G. A. Timco, F. Tuna, G. F. S. Whitehead and R. E. P. Winpenny, Chem. Commun., 2011, 47, 6251-6253.

5 The Chemistry of the Actinide and Transactinide Elements, ed. L. R. Morss, N. Edelstein and J. Fuger, Springer-Verlag Berlin, Germany, $3^{\text {rd }}$ edn., vol 1-5, 2006.

6 (a) R. A. J. Driessen, F. B. Hulsbergen, W. J. Vermin and J. Reedijk, Inorg. Chem. 1982, 21, 3594 -3597. (b) P. Nugent, Y. Belmabkhout, S. D. Burd, A. J. Cairns, R. Luebke, K. Forrest, T. Pham, S. Ma, B. Space, L. Wojtas, M. Eddaoudi and M. J. Zaworotko, Nature, 2013, 495, 80-84.

7 V. Mougel, L. Chatelain, J. Pécaut, R. Caciuffo, E. Colineau, J.C. Griveau and M. Mazzanti, Nat. Chem., 2012, 4, 1011.

8 T. Frot, S. Cochet, G. Laurent, C. Sassoye, M. Popall, C. Sanchez and L. Rozes, Eur. J. Inorg. Chem., 2010, 5650-5659.

9 a) Sheldrick. G. M., Acta Crystallogr., 2015, C71, 3-8; b) O. V. Dolomanov, L. J. Bourhis, R. J. Gildea, J. A. K. Howard, H. Puschmann,. J. Appl. Cryst., 2009, 42, 339-341.

10 (a) L. Brammer, E. A. Bruton, and P. Sherwood, Cryst. Growth Des., 2001, 1, 277-290; (b) L. Brammer, F. Zordan, G. M. Espallargas, S. L. Purver, L. A. Marin, H. Adams and P. Sherwood, ACA Trans., 2004, 39, 114-122.

11 N. Hoshino, M. Nakano, H. Nojiri, W. Wernsdorfer and H. Oshio, J. Amer. Chem. Soc.., 2009, 131, 15100-15101.

12 (a) J-Y Kim, A. J. Norquist and D. O'Hare, Chem. Commun., 2002, 2198-2199; (b) P. M. Almond, L. Deakin, M. J. Porter, A. Mar, and T. E. Albrecht-Schmitt, Chem. Mater., 2000, 12, 3208-3213; (c) P. M. Almond, L. Deakin, A. Mar, and T. E. Albrecht-Schmitt, Inorg. Chem., 2001, 40, 886-890.

13 R. J. Francis, P. S. Halasyamani, J. S. Bee, and D. O'Hare, J. Am. Chem. Soc., 1999, 121, 1609-1610.

14 W. Ren, H. Song, G. Zi and M. D. Walter, Dalton Trans., 2012, 41, 5965-5973.

15 N. F. Chilton, R. P. Anderson, L. D. Turner, A. Soncini and K. S. Murray, J. Comput. Chem., 2013, 34, 1164-1175.

16 M. L. Baker, A. Bianchi, S. Carretta, D. Collison, R. J. Docherty, E. J. L. McInnes, A. McRobbie, C. A. Muryn, H. Mutka, S Piligkos, M. Rancan, P. Santini, G. A. Timco, P. L. W. TregennaPiggott, F. Tuna, H. U. Güdel and R. E. P. Winpenny, Dalton Trans., 2011, 40, 2725-2734.

17 J. D. Rinehart, T. D. Harris, S. A. Kozimor, B. M. Bartlett and J. R. Long, Inorg. Chem., 2009, 48, 3382-3395.

18 B. S. Newell, A. K. Rappe and M. P. Shores, Inorg. Chem., 2010, 49, 1595-1606.

19 B. M. Gardner, D. M. King, F. Tuna, A. J. Wooles, N. F. Chilton and S. T. Liddle, Chem. Sci., 2017,8, 6207-6217

20 S. Stoll and A. Schweiger J. Magn. Reson. 2006, 178, 42-55.

21 S. T. Ochsenbein, F. Tuna, M. Rancan, R. S. G. Davies, C. A. Muryn, O. Waldmann, R. Bircher, A. Sieber, G. Carver, H. Mutka, F. Fernandez-Alonso, A. Podlesnyak, L. P. Engelhardt,
G. A. Timco, H. U. Güdel and R. E. P. Winpenny, Chem. Eur. J., 2008, 14, 5144-5158.

22 S. Piligkos, H. Weihe, E. Bill, F. Neese, H. El Mkami, G. M. Smith, D. Collison, G. Rajaraman, G. A. Timco, R. E. P. Winpenny and E. J. L. McInnes, Chem. Eur. J., 2009, 15, 31523167.

23 F. Moro, D. Kaminski, F. Tuna, G. F. S. Whitehead, G. A. Timco, D. Collison, R. E. P. Winpenny, A. Ardavan and E. J. L. Mclnnes, Chem. Commun., 2014, 50, 91-93. 